\title{
Right ventricular monophasic action potentials in patients with long QT syndrome
}

\author{
S. GAVRILESCU AND C. LUCA \\ From the Department of Internal Medicine and Cardiology, Institute of Medicine, Timisoara, Romania
}

SUMMARY In 3 patients with the long QT syndrome, one caused by quinidine and 2 of congenital origin, right ventricular monophasic action potentials were excessively prolonged and of varying shapes in different recording sites. In addition, effective refractory periods of the ventricular muscle were abnormally long.

The prolongation of the QT interval associated with syncopal attacks can be encountered in two different situations: the long QT syndrome of congenital origin (Jervell and Lange-Nielsen, 1957; Romano et al., 1963; Ward, 1964; Phillips and Ichinose, 1970) and the acquired form (Motté et al., 1970; Reynolds and Vander Ark, 1976). The latter may be found in association with various conditions such as atrioventricular block, sinus bradycardia, or the use of drugs of which quinidine, phenothiazines, and amiodarone are examples. Though a totally different pathogenic mechanism was suggested for these two syndromes, the common clinical and electrocardiographic features must have a common electrophysiological basis.

In this paper we present our findings in 3 patients with this syndrome in whom monophasic action potentials were recorded from the right ventricle.

\section{Methods}

The technique for recording monophasic action potentials was presented in a former paper (Gavrilescu et al., 1972). Close bipolar suction electrodes were passed percutaneously and positioned in the right ventricle. Applying gentle pressure an injury current was obtained. Suction applied with a simple device fixed the electrode in the chosen position and made possible the recording of the monophasic action potential. The negative pressure within the suction system was about $46.5 \mathrm{kPa}$; it was applied for periods of 2 minutes in order to avoid endocardial lesions. Only stable tracings with an amplitude exceeding $25 \mathrm{mV}$, and not distorted by artefacts, were analysed. The recordings were obtained from lateral wall, base, septal wall, and apex of the

Received for publication 12 September 1977 right ventricle. Monophasic action potential duration was measured at 90 per cent of repolarisation. The refractory period of the right ventricular myocardium was determined using the extra-stimulus method (Wit et al., 1970) and was synchronised with the monophasic action potential recordings. The stimulus strength of the test impulse was twice the diastolic threshold. Both monophasic action potential recordings and refractory period determination were performed at various cycle lengths.

\section{Subjects}

CASE 1

A 49-year-old woman with mitral valvular disease and atrial fibrillation was converted to sinus rhythm by DC shock. In the next few hours she developed syncopal attacks, after $1 \mathrm{~g}$ quinidine sulphate (Fig. 1B). A prolonged QT interval was noted immediately after the cessation of ventricular tachycardia (Fig. 1A and B). Monophasic action potential recordings (Fig. 2) were then obtained. There were no electrolyte disturbances, and the QT interval returned to normal values after 72 hours (Fig. 1C).

CASE 2

A previously healthy 32-year-old woman was referred to us for cardiac evaluation following an episode of syncope caused by ventricular fibrillation. Frequent multiform ventricular beats, a prolonged QT interval, and alternation of the $T$ wave had been noted after her resuscitation (Fig. 3A and B). On admission there were no abnormal findings with the exception of the long QT interval and inverted $T$ waves (Fig. 3A). She had normal hearing. The electrophysiological study was performed and monophasic action potentials recorded at different sites in the right ventricle showed varying durations and shapes (Fig. 4). 


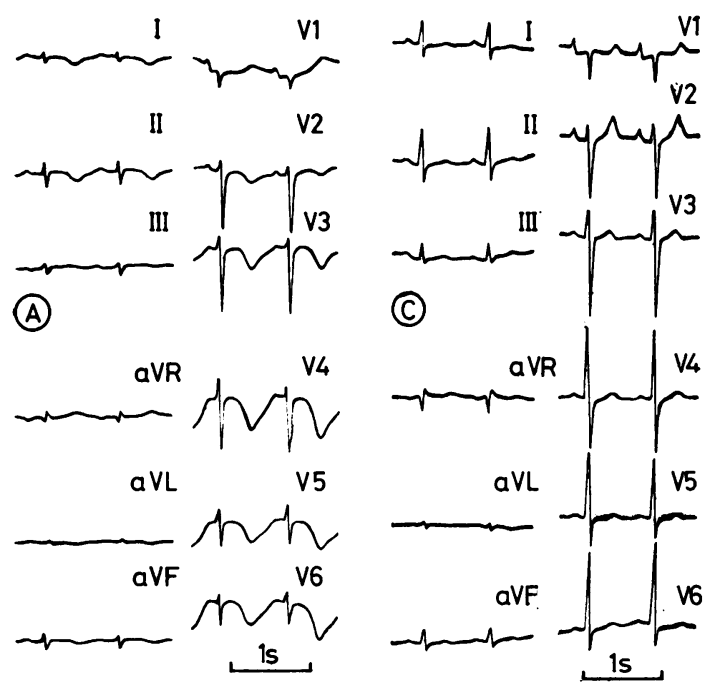

(B) นruruh

Fig. 1 Case 1. Surface electrocardiogram showing: (A) long $Q T$ interval and bizarre $T$ and $U$ waves, quinidine induced; $(B)$ ventricular tachycardia during syncopal attacks; and $(C)$ reversion to normal $Q T$ interval after drug withdrawal.

CASE 3

This case has been reported elsewhere (Gavrilescu and Luca, 1976). A 17-year-old boy had repeated attacks of ventricular tachycardia, the arrhythmia being interpreted as caused by re-entry within the

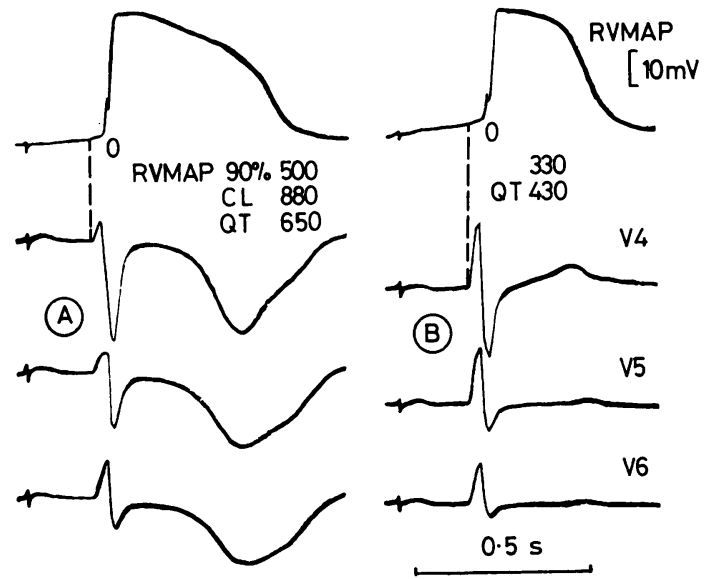

Fig. 2 Case 1. Right ventricular monophasic action potential recording ( $R V M A P):(A)$ during prolonged $Q T$ interval, and $(B)$ after reversion to normal. $C L$, cycle length.

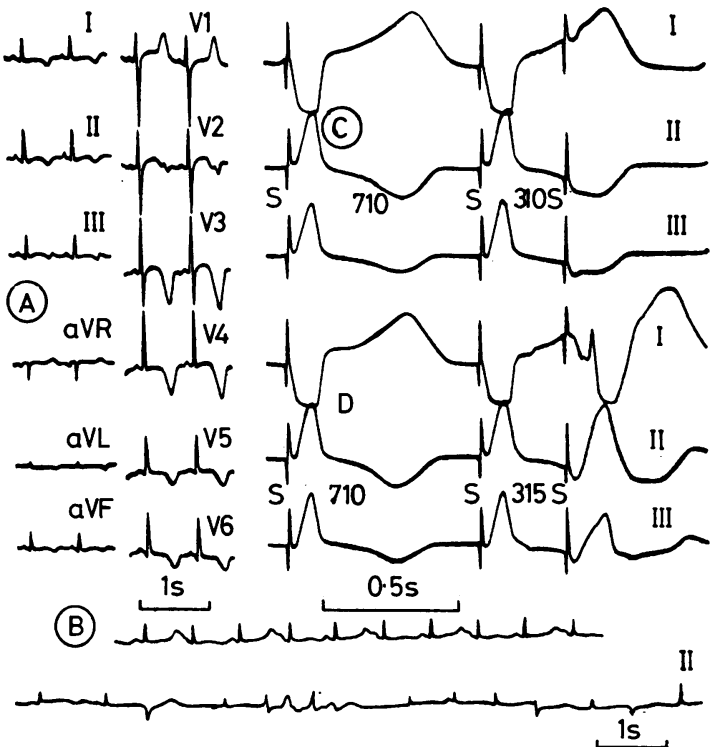

Fig. 3 Case 2. Surface electrocardiogram at admission $(A)$, with $T+U$ wave alternans and multiform ventricular ectopic beats $(B)$, and the determination of the refractory period of the right ventricle. $(C)$ effective refractory period, $310 \mathrm{~ms}$; (D) functional refractory period, $315 \mathrm{~ms}$.

bundle-branches. At the cessation of some of the arrhythmic episodes he showed a prolonged QT interval and inverted $T$ waves. Electrophysiological study was performed during such a period and the tracings were similar to those obtained in case 2 (Fig. 5). Monophasic action potential recordings from the apex and septal wall of the right ventricle showed a second deflection (Fig. $5 \mathrm{C}$ ), which became more apparent at a faster driving rate (Fig. 5D).

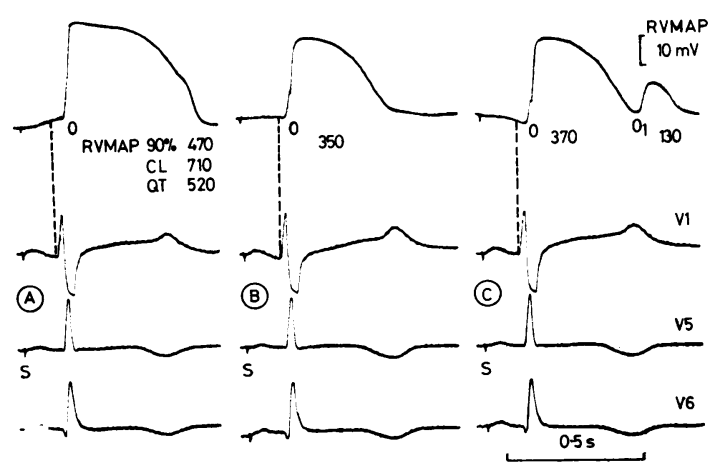

Fig. 4 Case 2. Right ventricular monophasic action potential recordings ( $R V M A P$ ) from: $(A)$ lateral wall, $(B)$ base, and $(C)$ apex and septal wall. 

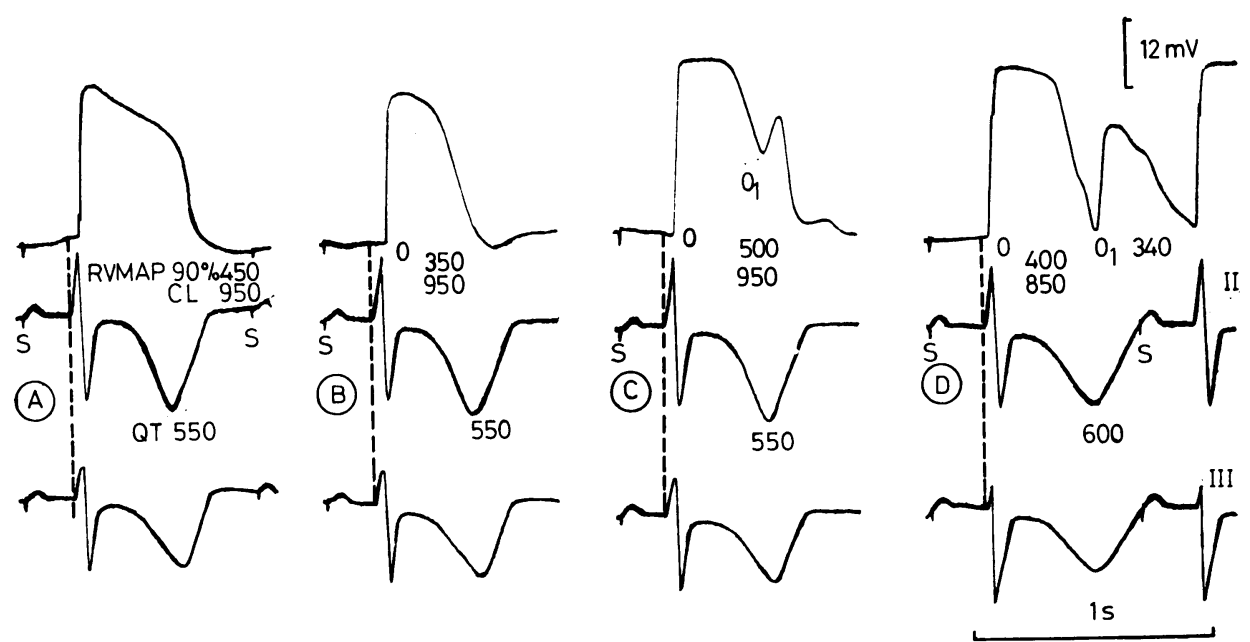

Fig. 5 Case 3. Right ventricular monophasic action potential recordings (RV MAP) from: $(A)$ lateral wall, $(B)$ base, $(C)$ apex and septal wall, and $(D)$ during pacing at a faster rate $(C L=850 \mathrm{~ms})$. In $D$ the second monophasic action potential deflection $\left(O_{1}\right)$ was detached and became more apparent. (For more details see the text.)

\section{Results}

Our findings are shown in the Table and in Figs 1 to 5 . All patients had abnormally prolonged monophasic action potential duration in comparison with the values found in patients with regular sinus rhythm (Olsson, 1971, 1972). Differences in duration of the monophasic action potential, recorded at various ventricular sites, were between 120 and 175 $\mathrm{ms}$ in cases 2 and 3, and in case 1 no such differences could be found. In cases 2 and 3 there was a second deflection $\left(0_{1}\right)$ during the late repolarisation phase in the monophasic action potential recordings
(Fig. 4C and Fig. 5C and D). Such differences between recordings in the same subject are an 0 unusual finding, as are the differences in the shape of the recordings from one site to the other. Refractory periods were also prolonged (Fig. 3C), and differences between the effective refractory periods recorded in the various parts of the right ventricle were also abnormal in comparison with previous data obtained in man (Guss et al., 1976).

\section{Discussion}

Several types of the long QT syndrome have been

Table Data obtained with right ventricular MAP recordings and right ventricular refractoriness in 3 patients with long $Q T$ syndrome

\begin{tabular}{|c|c|c|c|c|c|c|c|c|c|c|}
\hline \multirow[t]{2}{*}{$\begin{array}{l}\text { Case } \\
\text { no. }\end{array}$} & \multirow{2}{*}{$\begin{array}{l}\text { Cycle } \\
\text { length } \\
\text { (ms) }\end{array}$} & \multirow{2}{*}{$\begin{array}{l}Q T \\
\text { interval } \\
(m s)\end{array}$} & \multirow{2}{*}{$\begin{array}{l}Q T_{\mathrm{c}} \\
\text { interval } \\
(\mathrm{ms})\end{array}$} & \multicolumn{3}{|c|}{$\begin{array}{l}R V M A P 90 \text { per cent } \\
(\mathrm{ms})\end{array}$} & \multicolumn{3}{|c|}{$\begin{array}{l}R V E R P \\
(m s)\end{array}$} & \multirow[t]{2}{*}{ Aetiology } \\
\hline & & & & $A$ & $B$ & $C$ & $A$ & $B$ & $C$ & \\
\hline \multirow{4}{*}{1} & 1000 (SR) & 700 & 0.70 & 525 & 525 & 525 & - & - & - & \multirow{3}{*}{ Quinidine } \\
\hline & 880 & 650 & 0.69 & 500 & 500 & 500 & 420 & 420 & - & \\
\hline & 750 & 610 & 0.71 & 475 & 475 & 475 & 400 & 400 & 一 & \\
\hline & 750 (SR) & 530 & 0.58 & 480 & 365 & 360 & - & - & - & \multirow{3}{*}{ Congenital } \\
\hline \multirow[t]{2}{*}{2} & 710 & 520 & 0.61 & 470 & 350 & 370 & 415 & 310 & 350 & \\
\hline & 650 & 480 & 0.60 & 450 & 325 & 355 & 395 & 295 & 325 & \\
\hline \multirow{3}{*}{3} & $1200(\mathrm{SR})$ & 600 & 0.55 & 460 & 370 & 510 & - & - & - & \multirow{3}{*}{ Congenital } \\
\hline & 950 & 550 & 0.56 & 450 & 350 & 500 & 385 & 295 & - & \\
\hline & 850 & 600 & 0.65 & 430 & 325 & 400 & 370 & 285 & - & \\
\hline
\end{tabular}

Abbreviations: A, B, and C represents different recording sites from lateral wall (A), base (B), and apex and septal wall (C) of the right ventricle;

RV ERP, right ventricular effective refractory period;

RV MAP, right ventricular monophasic action potential;

SR, sinus rhythm. 
described: the heritable syndrome, with or without deafness, and the acquired forms. The basis of the congenital syndrome has been assumed to lie in pathological changes in the conducting tissue (Phillips and Ichinose, 1970) or in functional modifications caused by abnormalities in the repolarisation of the myocardial fibres secondary to metabolic disturbances (Schwartz et al., 1975), by an abnormal response to neurogenic stimuli, or an asymmetrical sympathetic stimulation of the ventricular muscle (James, 1969). The acquired long QT syndrome is secondary to conditions associated with bradycardia, hypokalaemia, or the use of drugs like quinidine, amiodarone, imipramine, and others (Motté et al., 1970). The suggested mechanism for the acquired long QT syndrome is a diffuse myocardial desynchronisation which is a contraindication to the administration of antiarrhythmic drugs such as propranolol, ventricular pacing being the treatment of choice in such cases (Schwartz et al., 1975). There are few electrophysiological studies in this syndrome. Wellens et al. (1972) described a girl with the congenital syndrome who developed ventricular fibrillation on arousal from sleep by auditory stimuli. Functional refractory periods of both ventricles were within normal limits, the greatest difference between various ventricular sites being $35 \mathrm{~ms}$. In our cases, however, right ventricular monophasic action potentials showed a distinct prolongation in comparison with the values found by Olsson in patients with regular sinus rhythm. Data from human ventricular refractoriness (Guss et al., 1976) suggested that our findings were also abnormal showing a considerable prolongation. That monophasic action potential prolongation was not artefactual, caused by changes in the intensity of suction applied during the recording procedure, is shown by the concurrent variations in right ventricular monophasic action potential duration and refractory periods measured with the help of the pacing technique. The asynchrony in refractoriness of ventricular muscle is suggested in our cases by the great differences between monophasic action potential recordings and refractoriness from various sites. The lack of such differences in the case described by Wellens may be explained by the fact that the QT changes occurred transiently preceding the syncopal attack, and the electrophysiological study was done while the QT interval was not greatly prolonged. In our patients the monophasic action potential recordings were performed during the period when QT prolongation was manifest. It is of interest to note that dispersion of repolarisation shown by monophasic action potential recordings was present in cases 2 and 3 with congenital long QT syndrome, while in case 1 with quinidine syn- cope, where the QT interval returned to normal after a few days, there was uniform prolongation of the right ventricular monophasic action potential duration. A prolongation of right atrial monophasic action potential under the effects of quinidine has been noted in man (Gavrilescu et al., 1972, 1976). In the dog quinidine prolongs right atrial and ventricular monophasic action potentials and also lengthens the refractory periods (Comşulea et al., 1976). However, in comparison with these data, the duration of the monophasic action potential and refractoriness of the right ventricle were excessively prolonged in our patient.

Abnormal monophasic action potentials may also explain changes in the $T$ wave during the long QT syndrome. It has been shown experimentally that small monophasic action potential duration changes are associated with $\mathrm{T}$ wave modifications (Autenrieth et al., 1975a, b). There may be an uneven contribution of different repolarisation regions to the $T$ wave shape. The type of monophasic action potential shown in Fig. 4C and Fig. 5C and D with a second deflection was observed in two cases. Though this deflection could be considered to be an artefact resulting from displacement of the catheter or modification of suction during the recording period, we believe that such a tracing is caused by delayed repolarisation of some myocardial zones, adjacent to the exploring electrode. This assumption is supported by the fact that the suction pressure was constant, the tracings were stable, and the longest monophasic action potential duration recorded in such cases was very close to the sum of both recorded complexes $\left(0\right.$ and $0_{1}$ in Fig. $4 \mathrm{C}$ and Fig. 5C). This phenomenon could be accentuated by variations of the cycle rate (Fig. 5D). The appearance of ventricular arrhythmias during the long QT syndrome may be triggered by critical differences of refractoriness between various ventricular areas. However, in case 1 , where the long QT syndrome was caused by quinidine this nonuniformity of electrophysiological events was not evident. We can not exclude the existence of such differences in the entire ventricular myocardium because of the limitations of the method. Although our studies cannot explain the detailed mechanism of the long QT syndrome, they allow the demonstration of uneven and delayed repolarisation of the ventricular myocardium as the common pathogenic mechanism of this syndrome.

\section{References}

Autenrieth, G., Surawicz, B., and Kuo, C. S. (1975a). Sequence of repolarization on the ventricular surface in the dog. American Heart fournal, 89, 463-469. 
Autenrieth, G., Surawicz, B., Kuo, C. S., and Arita, M. (1975b). Primary $T$ wave abnormalities caused by uniform and regional shortening of ventricular action potential in dog. Circulation, 51, 668-676.

Comșulea, L., Cristodorescu, R., Rocsin, M., and Gavrilescu, S. (1976). The effects of quinidine on the monophasic action potential of the right atrium and ventricle in dog. Agressologie, 17, 105-110.

Gavrilescu, S., Cotoi, S., and Pop, T. (1972). The monophasic action potential of the right atrium. Cardiology, 57, 200-207.

Gavrilescu, S., Dragulescu, S. I., Luca, C., Streian, C., Comsulea, L., and Popovici, V. (1976). The effects of quinidine on the monophasic action potential of the right atrium in patients with atrial fibrillation. Agressologie, 17, 111-118.

Gavrilescu, S., and Luca, C. (1976). Recurrent ventricular tachycardia due to re-entry within the bundle branches. Chest, 70, 387-389.

Guss, B. S., Kastor, J. A., Josephson, M. E., and Scharf, D. L. (1976). Human ventricular refractoriness: effects of cycle length, pacing site and atropine. Circulation, 53, 450-455.

James, N. T. (1969). Sympathetic discharge, QT prolongation and sudden death. Modern Concepts of Cardiovascular Disease, 38, 35-38.

Jervell, A., and Lange-Nielsen, F. (1957). Congenital deafmutism, functional heart disease with prolongation of the QT interval and sudden death. American Heart fournal, 54, 59-68.

Motté, G., Coumel, Ph., Abitbol, G., Dessertenne, F., and Slama, R. (1970). Le syndrome QT long et syncopes par 'torsades de pointe' (in French). Archives des Maladies du Coeur et des Vaissaux, 63, 831-853. Olsson, S. B. (1971). Monophasic Action Potentials of Right
Heart. Elanders Boktryckeri, Göteborg.

Olsson, S. B. (1972). Right ventricular monophasic action potential during regular rhythm. Acta Medica Scandinavica 191, 145-157.

Phillips, J., and Ichinose, H. (1970). Clinical and pathologic studies in the hereditary syndrome of a long QT interval, syncopal spells and sudden death. Chest, 58, 236-243.

Reynolds, E. W., and Vander Ark, C. R. (1976). Quinidine syncope and delayed repolarization syndromes. Modern Concepts of Cardiovascular Disease, 45, 117-122.

Romano, G., Gemme, G., and Pongiglione, R. (1963). $\vec{\omega}$ Aritmie cardiache rare dell'eta pediatrica. II. Accesi sincopali per fibrillazione ventricolare parossistica. (Presentazione del primo caso della letteratura pediatrica italiana) (in Italian). Clinica Pediatrica, 45, 656-683.

Schwartz, P. J., Periti, M., and Malliani, A. (1975). The long QT syndrome. American Heart fournal, 89, 378-390.

Ward, O. C. (1964). A new familial cardiac syndrome in children. Fournal of the Irish Medical Association, 54, 103-106.

Wellens, H. J. J., Vermeulen, A., and Durrer, D. (1972). Ventricular fibrillation occurring on arousal from sleep by $c \Omega$ auditory stimuli. Circulation, 46, 661-665.

Wit, A. L., Weiss, M. B., Berkowitz, W. D., Rosen, K. M., $\frac{\mathbb{D}}{\mathbb{D}}$ Steiner, C., and Damato, A. N. (1970). Patterns of atrioventricular conduction in the human heart. Circulation Research, 27, 345-359.

Requests for reprints to Professor S. Gavrilescu, Clinica I Medicala, Spital Judetean, Bul. St. Plavat Nr. 156, 1900 Timisoara, Romania. 